\title{
Atletas do século XXI: ou das fusões biotecnológicas nos atletas de alto rendimento
}

George Saliba Manske*

\begin{abstract}
Resumo: Este estudo tem como objetivo discutir as condições contemporâneas vinculadas às biotecnologias e suas relações com o esporte de alto rendimento, em especial, na configuração de um novo tipo de sujeito atleta. Para isso parte de um caso específico do esporte mundial para lançar questões referentes a esta problemática. Assume-se o pressuposto que as bases epistemológicas que organizam o esporte moderno são dualísticas, e acabam por classificar os sujeitos entre atletas normais ou paratletas, sendo, portanto, incapazes de lidar com as transformações hodiernas referentes aos usos de tecnologias para a ampliação das potencialidades humanas. Desse modo, sugere-se, por fim, sobre a possibilidade de novas organizações do contexto esportivo de alto rendimento em âmbito internacional.
\end{abstract}

Palavras-chave: Esporte. Atletas. Biotecnologia.

\section{0 caso Pistorius}

Quando o corredor sul-africano Oscar Pistorius melhorou seu tempo na prova dos 400m do atletismo, em abril de 2011, alcançando inclusive a marca necessária para competir na Olimpíada de Londres em 2012, renovou-se uma polêmica no âmbito da Federação Internacional de Atletismo (IAAF), do Comitê Olímpico Internacional (COI), da Agência Mundial Anti-Doping (WADA-AMA) e dos mais diversos setores envolvidos com o esporte de alto rendimento: Poderia Pistorius participar da Olimpíada de 2012? Tal como previsto Pistorius não apenas participou da Olimpíada de Londres como, principalmente,

\footnotetext{
"Professor do curso de Educação Física da Universidade do Vale do Itajaí (UNIVALI), Itajaí, SC, Brasil. E-mail: gsmanske@yahoo.com.br
} 
disputou uma final olímpica no revezamento 4 x 400m com sua equipe, a África do Sul, tornando-se o primeiro atleta biamputado a disputar uma final olímpica.

A polêmica envolvendo Pistorius ocorreu pelo fato deste atleta permear, violar, ameaçar e transcender os distintos critérios e categorias utilizadas atualmente para os participantes dos Jogos Olímpicos, seja no âmbito da Olimpíada tradicional, destinada aos atletas tidos como 'normais', ou a Paralimpíada, destinada aos atletas paralímpicos, sujeitos tidos com alguma deficiência física. Pistorius incorpora, por assim dizer, a expressão da mobilidade entre fronteiras do que é um atleta normal e um atleta paralímpico, a partir da materialidade das promessas biotecnológicas tocantes às transformações e otimizações do corpo do homem contemporâneo.

A figura desse atleta representa, por assim dizer, uma ciborguização do humano. Tal junção entre corpo e aparato tecnológico está para além da célebre figura de acoplamento de partes mecânicas no corpo, na medida em que as próteses de Pistorius tornam-se sua extensão corporal, seu próprio corpo. Como argumenta Couto (2001, p. 88), "esses novos componentes técnicos integrados, con-fundidos na estrutura física, promovem uma nova natureza, uma outra realidade corporal".

Esta outra realidade corporal, baseada numa ciborguização do humano, parte do pressuposto de que na atualidade temos a possibilidade de existência de criaturas cibernéticas, as quais são "híbridos de máquina e organismo, criaturas de realidade social e ficção", ou ainda e no limite, são entes "simultaneamente animais e máquinas, que vivem em mundos ambiguamente naturais e artificiais" (HARAWAY, 1984, p. 1).

A partir dessas discussões um problema que estava fecundando e fermentando no cenário mundial do esporte de alto rendimento vem à tona e torna-se publicamente uma polêmica generalizada: como lidar com as articulações e usos da biotecnologia contemporânea (inclusive a biotecnologia gênica) nos esportes de alto rendimento? Haveria um lugar específico para este tipo de atleta, 
não mais concebido como normal e, tampouco, como deficiente, mas como um ser humano otimizado? Seria necessário organizar outro tipo de Jogos Olímpicos para uma nova categoria de atleta emergente, em oposição aos Jogos Olímpicos tradicionais e as Paralimpíadas? Ou ainda: as próprias Paralimpíadas desenvolver-se-ão, inevitavelmente, para um tipo de competição que incorpore hibridações orgânico-tecnológicas nos sujeitos atletas?

Os efeitos destes desdobramentos culturais são incontáveis e vão desde um novo tipo de conhecimento sobre o ser humano e suas práticas esportivas, voltadas para a o alto rendimento, até mercados de marketing e produtos esportivos que incrementem o desempenho de indivíduos não atletas, passando por atividades até mesmo corriqueiras de nossas práticas corporais de lazer, saúde e entretenimento. Entretanto, como bem ressalta Miah (2006), a arena esportiva parece ser um lugar privilegiado para os usos e aplicações das estruturas e saberes tecnológicos contemporâneos, levando, talvez, há novos questionamentos sobre o futuro e direção do esporte internacional de alto nível.

Tomando tais apontamentos e fatos contemporâneos sobre esporte e tecnologias como ponto de partida, e contornando inicialmente este tema a partir de algumas reflexões sobre o lugar das transformações do corpo na sociedade, de um modo geral, e do atleta de alto rendimento, de modo mais restrito, principalmente no que concerne às categorias tradicionais de classificação destes sujeitos (atletas normais ou paratletas), é que proponho um problema a ser desenvolvido ao longo deste ensaio: como se configura, na atualidade e a partir das condições biotecnológicas contemporâneas, novas possibilidades de ser atleta ${ }^{1}$ ?

Cabe ressaltar que tais possibilidades se ancoram nas transformações contemporâneas de saberes tecnológicos e nas

\footnotetext{
${ }^{1}$ Ao longo deste ensaio usarei conceitos e concepções de diferentes autores para me referir ao atleta que faz/pode fazer uso das tecnologias da vida para ampliar seu potencial. Cabe registrar que não entendo tais termos como correlatos, e tampouco como sinônimos, mas sim, que tais conceitos partem de um ponto de compreensão em comum: a construção de novas subjetividades humanas a partir dos usos das biotecnologias contemporâneas.
} 
possibilidades de intervenção no ser humano. Na condução deste ensaio discuto, num primeiro momento, as condições sociais e culturais que possibilitam tais argumentos para, ao final, ensaiar sobre o emergente atleta biotecnológico.

\section{POSSIBILIDADES BIOTECNOLÓGICAS}

O termo biotecnologia foi utilizado inicialmente para se referir às técnicas que intervinham de maneira precisa e controlada nos processos biológicos de desenvolvimento de produtos alimentícios, tais como o vinho, o pão e os derivados lácteos (BORÉM; SANTOS, 2004, p. 17). Porém, na atualidade, o termo biotecnologia é amplamente utilizado em diversas situações, o que lhe confere diferentes definições e acarreta uma serie de possibilidades de produção, tais como a fabricação de antibióticos, vacinas, testes genéticos e medicamentos diversos, bem como de campos de intervenção como a engenharia e o aconselhamento genético.

Mesmo à época do desenvolvimento da biotecnologia já se apontava para a emergência de um ramo da biotecnologia que dominaria os investimentos, as pesquisas, as atividades econômicas e cientificas e, inclusive, o imaginário social, a saber, a engenharia genética com ênfase na clonagem de seres vivos e no código genômico, os quais partem, primordialmente, da composição e compreensão do que é um genoma.

Um genoma é todo material genético, ou genes, resultantes do conjunto de cromossomos de um indivíduo, ou organismo vivo (RABINOW, 1999, DIAS, 2011). O mapeamento do genoma humano foi um projeto que recebeu altos incentivos e financiamentos de uma série de organizações governamentais e não-governamentais, as quais fundaram o Consórcio Internacional de Sequenciamento do Genoma Humano (DIAS, 2011). O resultado final de sua investida foi divulgado em 2004 através de uma publicação no periódico Nature (DIAS, 2011). 
Torna-se necessário ressaltar que a maioria dos autores que discutem a biotecnologia se inscrevem, especificamente, no campo das ciências naturais, de modo geral. Sendo assim, torna-se evidente que eles não se propõem a tensionar este campo de conhecimento, mas, antes, buscam descrevê-lo em seu surgimento e funcionamento. Cabe destacar, contudo, que uma série de outros autores, inclusive de outros campos de conhecimento, vem discutindo as relações das biotecnologias contemporâneas a partir de perspectivas teóricas distintas ${ }^{2}$.

Rose (2007), por exemplo, destaca que as pesquisas e desenvolvimentos da biotecnologia geram lucros bastante altos no campo econômico, através da criação de patentes de remédios ou de outros produtos de propriedade intelectual. Porém, tais desenvolvimentos não acarretam melhorias diretas à saúde ou diminuem o adoecimento da maioria da população, sendo essas finalidades menos glamorosas do que aquelas concernentes ao campo da estética, por exemplo. Ortega (2007, p. 385) corrobora com este argumento na medida em que denuncia o "aspecto elitista das propostas de superação do corpo pelas novas biotecnologias, pois excluem quatro quintos da humanidade que não possuem acesso às tecnologias $[\ldots] "$.

Além do mais, ressalta Rose (2007, p. 4), tais empreendimentos biotecnológicos enfatizam o envolvimento dos sujeitos num cuidado e gerenciamento de si, através de uma responsabilização do indivíduo, que deve ser seguida para um cuidado do futuro na medida em que passamos a ter "um qualitativo incremento de nossas capacidades para gerenciar nossa vitalidade, desenvolvimento, metabolismo, organismo e cérebro".

Outra contribuição importante para esta discussão são aquelas realizadas por Rabinow (1999). O autor analisa as mudanças sociais implantadas pela biotecnologia em diferentes frentes, sendo que a mudança nas relações sociais parece ocupar um lugar de maior

\footnotetext{
${ }^{2}$ Quanto aos autores que discutem sobre biotecnologia no campo das ciências naturais vide Borém e Santos (2004), Scriban (1985), Bu'lock, 1991. Por outro lado, no campo das ciências humanas, sugiro Rose (2007), Rabinow (2002), Sloterdijk (2006) e Rifikin (1999).
} 
destaque. $\mathrm{O}$ autor argumenta que a biotecnologia, em especial o Projeto Genoma, conformará novos vetores de socialização, a partir dos quais pessoas e grupos se organizarão com base nos conhecimentos genômicos, que vão desde o reconhecimento do outro pela ordem da informação genética até mesmo a possibilidade de exclusão social que pode ocorrer a partir desse novo modo de conceber a vida, o outro, a si mesmo e a população.

As discussões acerca dos tensionamentos e possibilidades de análises da biotecnologia contemporânea podem ocorrer em várias frentes de problematização. Entre elas, destaco aquelas que se referem à discussão proposta neste ensaio, a saber, as aplicações das biotecnologias no esporte de alto rendimento. No contexto dessas aplicações há recorrência de usos das mais diversas intervenções no corpo do atleta, desde aquelas relacionadas às vestimentas até mesmo as alterações genéticas, passando pelo uso de diferentes substâncias e métodos de aplicação.

O estudo de Dias (2011) discute contundentemente esses debates sobre as manipulações genéticas. O referido autor destaca que na era da medicina genômica a tecnologia do sequenciamento do genoma tornou possível "caracterizar geneticamente os fenômenos do esporte de alto rendimento" (DIAS, 2011, p. 63). A tecnologia desenvolvida pelo sequenciamento tornou realidade a manipulação de genes humanos. O que inicialmente estava restrito para fins terapêuticos e medicinais, agora, com o avanço da técnica e dos saberes pertinentes a esse campo, também pode ser aplicado no esporte. Assim, passou-se a denominar de doping genético àquelas estratégias de manipulação genética com finalidades de aumento do rendimento esportivo de atletas de alto nível.

No entanto, Dias (2011) também ressalta que grande parte das informações veiculadas sob o nome de doping genético não configura, de fato, tal manipulação. Esse frenesi acerca das possibilidades de alteração genética em desportistas é fruto de interpretações científicas mal formuladas e exploração midiática de temas que despertam curiosidade e alvoroçam o imaginário social. Daí que aquilo 
que se pode comprovar cientificamente sobre doping genético está muito distante do que é veiculado e disseminado pelo senso comum (DIAS, 2011).

Ao contrário do que afirma Dias (2011), a Agência Mundial Anti-Doping (WADA-AMA) compreende que o doping genético é uma realidade. Estudos financiados pela própria Agência apontam possibilidades de realização desse tipo de procedimento através da "transferência de genes". Esse procedimento implica em transferir determinados tipos de genes de um sujeito para outro, através de um vírus que não faria mal ao sujeito a ser modificado, pois teriam 'apenas' a função de carregar e inserir novos genes nos indivíduos alvos de modificação. Assim, destaca a World Anti-Doping Agency (2005, p. 4), há experimentos em que se inserem

\begin{abstract}
genes que produzem o fator de crescimento similar ao da insulina 1 (IGF-1), que ajuda os músculos a crescer e a reparar-se a eles mesmos. Os genes, transferidos ao corpo por um vírus inócuo, produzem mais IGF-1 do que aqueles que normalmente o corpo produz, estimulando o crescimento muscular.
\end{abstract}

Devido a tais possibilidades tecnológicas de doping esportivo é que a WADA-AMA instituiu, em 2003, uma política de proibição ao doping genético, alertando sobre as dificuldades de detectar todos os tipos de manipulação dessa ordem (MIAH, 2006).

A partir dos relatos da própria WADA-AMA talvez se possa dizer que os argumentos de Dias (2011) estão um pouco distantes das atuais possibilidades biotecnológicas gênicas no esporte. Apresentei estas duas posições sobre doping genético, a saber, negando essa possibilidade e afirmando tal possibilidade, na direção de exemplificar o quanto, no campo da manipulação genética aplicada ao esporte, há inúmeras controvérsias quanto às possibilidades, realidades e ficções relacionadas a esse tema.

No tocante a esse estudo não interessa se tal procedimento de doping genético é realmente comprovável cientificamente ou se de fato existe, mas, sim, como que se pode configurar a emergência de 
um novo tipo de atleta, a saber, o atleta biotecnológico. Assim, tais argumentos seguem na direção de compor uma rede que possibilita a construção deste novo sujeito atleta. A seguir, amplio a discussão elencando outros elementos contemporâneos referentes as novas condições culturais para o atleta do século XXI, tensionando o par de base dualística 'normal-deficiente' que organiza as concepções dos esportes e atletas contemporâneos.

\section{C(R)OMO SOMOS: A CONSTITUIÇÃO de SUJEITOS SUI 'GENE'RIS}

Sloterdijk (2006, p. 2), em Conferência proferida na Universidade de Harvard, discutiu o "apocalipse do homem" moderno a partir das tecnologias da vida que hoje se apresentam, ou, dito a partir de suas palavras, "o Ser está desaparecendo sob uma profusão de bases epistemológicas". Para o autor, o atual estado de desenvolvimento da cultura tecnológica está "produzindo um novo estado de agregação da linguagem e da escritura, estado que tem pouco em comum com as interpretações tradicionais por parte da religião, da metafísica e do humanismo" (SLOTERDIJK, 2006, p. 2).

Assim, a era dos "códigos digitais e das transcrições genéticas" tem imposto ao ser humano uma condição que não está mais posta plano da transmissão/assimilação de conhecimentos do exterior para o interior humano, numa relação de apropriação e incorporação de saberes tradicionalmente concebidos numa relação dualística, mas, está marcada e organizada num plano de hibridação entre exterior e interior, numa configuração completamente diferente daquela até então experimentada pelo ser humano em sociedade (SLOTERDIJK, 2006).

Os modos de organização do mundo a partir dos dualismos ${ }^{3}$ tradicionais, tais como cultura/natureza, sujeito/objeto, corpo/alma, espírito/matéria, não podem mais ser usados para configurar um

\footnotetext{
${ }^{3}$ Para uma breve explicação desta concepção poderia afirmar que o dualismo é uma maneira de pensar originada e originária da modernidade, na qual se concebe o mundo e o ser humano a partir da separação e oposição das coisas - incluindo aqui conceitos, sistemas de pensamentos, objetos - em pares opostos (FAUSTO-STERLING, 2001)
} 
novo tipo de sujeito emergente, a saber, um sujeito híbrido, com capacidade de fazer a si mesmo de maneira diferente daquela 'naturalmente dada'. Como bem destaca Haraway (1984, p. 3) "a natureza e a cultura são remodeladas e a primeira já não pode ser um recurso disposto a ser apropriado e incorporado pela segunda". Assim, a separação e a relação entre natureza e cultura na constituição do Ser deixam de ser o ponto de análise das construções das subjetividades. $\mathrm{O}$ ponto das análises passa a ser a hibridação do próprio ser enquanto fabricante de si e do mundo, naquilo que construiu enquanto conhecimento para compreender e construir as coisas ao seu redor e a si mesmo, a saber, os "princípios de informação".

Os "princípios de informação" citados pelo autor se referem aos sistemas, culturas, recordações, inteligências artificiais que atuam na organização do mundo e na maneira como nos entendemos nele. Organizam-se como se houvesse não mais uma distinção entre corpo e pensamento ou matéria e informação, mas uma organização que é da ordem da "matéria informada". Como ele bem exemplifica, "a afirmação há genes só pode ser entendida como o produto de uma situação nova: mostra a transferência exitosa do princípio da informação para a esfera da natureza" (SLOTERDIJK, 2006, p. 8).

Para Sloterdijk (2006), os "princípios de informação" estão na base do conhecimento contemporâneo, pois transitam entre os pensamentos e as coisas, atravessam transversalmente o que antes era um 'par' (dualismo) de 'polo a polo' (binarismo), agindo como um terceiro valor ou vetor, como outra rota ou alternativa para compreender e produzir o mundo e os sujeitos. Desse modo, ao colocar em xeque as concepções tradicionais, o autor procura fundir as categorias tradicionalmente usadas pelos sujeitos para compreender o mundo e a si mesmos.

A fundição das categorias dualísticas citada por Sloterdijk (2006) ganha força nos argumentos de Sibilia (2002). Para a autora, ao analisarmos as alterações promovidas pela biotecnologia através de recorrências contemporâneas, percebemos claramente a "intenção de superar a condição humana, as falências do corpo orgânico, os 
limites espaciais e temporais ligados à sua materialidade. Em síntese: busca-se transcender a humanidade" (SIBILIA, 2002, p. 87).

E o campo em que a busca da transcendência do humano ou da fundição das categorias dualísticas tradicionais se revela mais promissor e espetacular é o das tecnologias gênicas (SLOTERDIJK, 2002). Esse campo abre possibilidades e condições de manipulação do homem por si mesmo, a partir de uma série de interferências artificiais, isso porque a biotecnologia gênica tende a "identificar a mente, o corpo e suas partes às matérias primas manipuláveis e controláveis" (MACHADO E SILVA, 2008, p. 52).

A articulação entre "princípios da informação" e possibilidades de polivalência constitui os vetores de força da constituição de novas subjetividades, a partir das quais se abre espaço e possibilidades para um ser humano enquanto composição, fluído, operável, manipulável e transformável a partir de seus próprios interesses e das capacidades tecnológicas ofertadas.

O ser humano atleta, que se encontra nestas condições é, por assim dizer, fruto também desta polivalência, tornando-se um ser que está além e aquém do atleta normal ou do paratleta, não se situando mais neste dualismo desportivo, mas encontrando-se, isso sim, num atravessamento entre eles, como uma terceira via, outra opção.

Talvez seja por esses fatos que Pistorius, caso descrito na introdução deste ensaio, acabe ocupando um não-lugar, ou ainda, um lugar que não pertence mais a um pólo (positivo, completo, como o atleta normal) ou outro (negativo, incompleto, como o do paratleta), mas pertence às possibilidades de abertura e configuração de um novo lugar, a ser ocupado por um "novo sujeito". Aqui, quiçá, resida a terceira via, o outro vetor, a possibilidade de um novo atleta. No entanto, cabe também perguntar: como regular, controlar e definir critérios para uma nova figura de atleta? Usar-se-á concepções bivalentes para conceber atletas híbridos em condições culturais 
polivalentes? Como tais possibilidades híbridas de constituição de sujeitos, a partir de novos vetores, se expressam na contemporaneidade?

Atualmente podemos encontrar no seio da sociedade grupos que não apenas aceitam essa possibilidade de novas formas de sujeição, através das biotecnologias contemporâneas, mas que buscam incorporar tais formas de pensar e existir em suas maneiras de viver, através de dados processos de subjetivação.

$\mathrm{Na}$ declaração de princípios da transhumanidade ${ }^{4}$ encontramos, por exemplo, manifestações que corroboram com o argumento do desenvolvimento de novos grupos e novas subjetividades. Assim, objetivos tais como "ampliar o potencial humano de superar o envelhecimento, deficiências cognitivas, o sofrimento involuntário, e nosso confinamento no planeta Terra", ou ainda, defender "o uso de técnicas que podem ser desenvolvidas para ajudar a memória, concentração e energia mental", ou aprimorar "terapias de extensão da vida, tecnologias de escolha reprodutiva, métodos de criogenia", e outros que ampliem e aperfeiçoem o ser humano são amplamente descritos como finalidades e princípios dessa declaração (HUMANITYPLUS, 2011).

As possibilidades de alteração do humano a partir das biotecnologias na busca de seu aperfeiçoamento, melhoria ou superação da condição humana, tal como acima referido, são analisados por Rose (2007) a partir do conceito otimização. Por otimização Rose (2007, p. 16-17) sugere o "controle do processo vital do corpo e da mente" através das biotecnologias contemporâneas. Assim, as biotecnologias, enquanto tecnologias de otimização, buscam um controle total do processo vital do humano.

\footnotetext{
${ }^{4} \mathrm{~A}$ declaração da transhumanidade foi originalmente criada em 1998 por um grupo de autores independentes e, posteriormente, modificada ao longo dos anos por diferentes autores e organizações. Esta declaração foi adotada pela organização Humanity+ em março de 2009 e defende, em linhas gerais, o uso ético de tecnologias para a superação das condições e limitações naturais do ser humano, a fim de ampliar suas potencialidades. A Humanity+é uma organização internacional sem fins lucrativos que defende os princípios da declaração da transhumanidade (HUMANITYPLUS, 2011).
} 
Poder-se-ia afirmar a partir do conceito de otimização que, frente às possibilidades de manipulação do ser humano por ele mesmo as finalidades do uso das biotecnologias não residem mais em curar doenças ou melhorar a saúde, mas em maximizar, realçar e incrementar as funções do seu próprio organismo a partir dos interesses e critérios de seus 'clientes'. Rose (2007, p. 20) ressalta que os sujeitos que aderem a essas possibilidades de intervenção são "consumidores, fazem escolhas na base de desejos que podem parecer triviais, narcisísticos ou irracionais, realizados não por uma necessidade médica, mas por um mercado e cultura consumidora".

Cabe ressaltar que este realçamento biotecnológico não está mais na ordem do acoplamento da robótica ou do computador no humano, tal como num pressuposto dualístico ou bivalente (SLOTERDIJK, 2006). Antes disso, ele está em outro marco, está em nível molecular, como destaca Rose (2007). Essas alterações ocorrem "no nível orgânico, para refazer a vitalidade por dentro". O ser humano não é menos biológico (como no caso do acoplamento de máquinas no corpo), mas é justamente o oposto, ele é "mais biológico" (ROSE, 2007, p. 20).

Embora não atenda plenamente a todos os argumentos citados por Rose (2007) no que se refere à otimização do corpo como, por exemplo, ter sido uma escolha do próprio sujeito, o caso de Pistorius parece ocupar, aqui, um lugar privilegiado para refletir sobre a concepção adotada pelo autor. Embora o atleta tenha acoplado as próteses em seu corpo, tal como num paradigma bivalente, essas próteses são denominadas de 'inteligentes', pois percebem o movimento do atleta e se adaptam às exigências desse movimento. Inclusive atletas normais reclamam das vantagens que as pernas de Pistorius lhe proporcionariam. Desse modo, Pistorius não é um atleta deficiente que apenas adaptou pernas mecânicas para sanar suas deficiências, ele tornou suas deficiências em maximização de suas potencialidades.

O doping genético funciona também nesse marco de otimização, na medida em que se "injetariam genes específicos no corpo a fim de incrementar a função de uma célula normal" (WORLD ANTI- 
DOPING AGENCY, 2005, p. 4). Nesse caso, a otimização não se dá pelo acoplamento de partes mecânicas ao corpo, elas ocorrem em nível molecular, com a inserção de novas informações que, "com o tempo", passam a ser do próprio corpo do atleta.

A nova condição de ser humano emergente representa, em diversos níveis, os aspectos contemporâneos de nossa cultura. Tais interferências ocorrem em múltiplos segmentos sociais, inclusive no âmbito dos esportes e na constituição de atletas.

\section{O esportista biOteCNOlÓGico}

Ante o exposto poderia continuar e reforçar a argumentação de que o esporte olímpico concebe e classifica os atletas a partir de um pensamento dualístico: de um lado, os atletas tidos como normais, sem deficiências, e de outro, os atletas tidos como deficientes, ou seja, os paralímpicos. Além disto, o pensamento dualístico ainda permanece quando se analisa somente os atletas paralímpicos, pois se entende que os mesmos são formados por acoplamentos de objetos em seus corpos, a fim de sanar suas deficiências.

Em oposição a estes atletas podemos citar os atletas biotecnológicos, os quais não se configuram por acoplamentos de objetos exteriores, mas pelo fato de que quando se une objetos e sujeitos criam-se 'objetos-sujeitos', um ser orgânico que não pertence a nenhuma categoria promulgada pelo esporte olímpico. Esta seria a "síntese do homem com a máquina, do natural com o artificial. É a coexistência ou justaposição desses elementos até então considerados incompatíveis ou conceitualmente ilegítimos" (COUTO, 2001, p. 94).

Esta possibilidade de problematizar e compreender tais recorrências contemporâneas sobre o humano e, em especial, sobre os atletas de alto rendimento, pode ser desenvolvida, sobretudo, a partir de campos de conhecimento que subvertem a lógica binária de atribuição de sentidos e significados aos fenômenos no mundo. Dentre estes campos de estudos baseio-me, neste ensaio, no pósestruturalismo. 
Para o movimento de pensamento ou atitude convencionada de pós-estruturalismo a linguagem adquire maior centralidade enquanto meio de produção de significados e, de certa forma, é radicalizada em relação à concepção desenvolvida nos trabalhos estruturalistas (SILVA, 1999). A linguagem, então, não apenas atua na significação das coisas e de seus significados - tampouco é entendida como descritora dos eventos materiais - porém, antes disso, "o processo de significação continua central, mas a fixidez do significado que é, de certa forma, suposta no estruturalismo, se transforma no pós-estruturalismo em fluidez, indeterminação e incerteza" (SILVA, 1999, p. 119).

Tal modo de pensar acarreta uma maneira diferente de conceber os atletas contemporâneos, que supera e transcende a lógica binária moderna que caracteriza os esportistas em atletas normais ou deficientes. O modo de pensar pós-estruturalista auxilia a compreensão e inclusão de outras possibilidades de sujeitos atletas, sejam esses ciborgues, híbridos, transhumanos, otimizados, ou outros modos que possam vir a assumir com o tempo ${ }^{5}$.

Pistorius, o caso emblema que abre este ensaio, é um típico representante do momento atual de esportistas de alto nível. $\mathrm{O}$ binarismo linguístico moderno, assentado no dualismo, não consegue dar conta de compreender e regular Pistorius. Outros exemplos também são emblemáticos desse tipo de situação, como o caso da corredora espanhola Maria Patiño, impedida de competir por seu país, a Espanha, na Olimpíada de Seul por ter realizado um exame que apontou a síndrome de insensibilidade ao andrógeno. Tal síndrome

\footnotetext{
${ }^{5} \mathrm{Ao} \mathrm{sugerir} \mathrm{que} \mathrm{o} \mathrm{dualismo} \mathrm{moderno} \mathrm{e} \mathrm{a} \mathrm{lógica} \mathrm{binária} \mathrm{conformam} \mathrm{uma} \mathrm{base} \mathrm{na} \mathrm{qual} \mathrm{se} \mathrm{assenta}$ a organização do esporte moderno não pretendo afirmar definitivamente que é somente nessa base que o esporte moderno se organiza, mas sim, de que tais formas de pensar o corpo e o esporte (assim como outros elementos da cultura) são marcadamente influenciadas pelos modos de pensamento dualístico e binário. Desse modo, reconheço que, mesmo no interior das práticas esportivas olímpicas e paralímpicas, existem também diferenciações e separações internas tais como categorias de esportistas separadas por gênero e peso (no caso do esporte olímpico), e deficiências e limitações (no caso do esporte paralímpico), as quais são organizadas na tentativa de estabelecer um dos princípios do projeto olímpico moderno, qual seja, o de igualdade de condições de disputa. Nesse ínterim, inclusive, há inúmeros esforços para a regulação dos usos de artificialidades no esporte, tais como roupas, aparelhos, medicamentos, acessórios e outros elementos que são analisados e controlados por federações internacionais e pela própria WADA-AMA na tentativa da manutenção de igualdades de disputa.
} 
caracteriza a atleta como portadora de cromossomo Y, e acarreta a ausência de ovários e útero, além de pequenos testículos entre os lábios vaginais (FAUSTO-STERLING, 2001). Tal caso representa a fragilidade dos critérios utilizados para determinar o sexo dos esportistas em eventos internacionais.

A partir dessas recorrências muitos questionamentos podem ser realizados levando em consideração as novas configurações de ser humano e atletas, principalmente quando as articulamos com os efeitos das biotecnologias.

Machado e Silva (2008, p. 175) chama a atenção para a compreensão do ser humano no âmbito da biotecnologia. Para a autora, "na biotecnologia, a categoria humano se expressa na sua identificação como 'ser vivo', como no projeto genoma humano, nas técnicas de fertilização in vitro, nas reparações clínicas e estéticas" e outros. Para ela esta concepção de ser vivo é diferente da concepção de organismo vivo ou ser humano. Quando se refere a organismo vivo a autora argumenta que tal termo remete a todo e qualquer organismo vivo despossuído de subjetividade. A categoria ser humano, por sua vez, remete a um ser oriundo da concepção moderna de sociedade, fabricado pela natureza e alterado pela cultura. Na categoria 'ser vivo' o 'humano-vivo' se torna um tipo de sujeito múltiplo, manipulável, assimétrico, flexível, sem limites.

Sloterdijk (2006, p. 16) corrobora com este pensamento quando argumenta que nesta nova configuração de ser humano não se trata da subjugação ou escravização do material/objeto pelo humano/sujeito (dualismo), mas de uma abordagem não dominante, para a qual o autor sugere o termo "homeotecnologia".

A "homeotecnologia" não compreende a matéria/objeto como algo em que se apoiam ou se colocam outras coisas, tal como se concebe a matéria-prima, ou ainda, o corpo do ser humano, mas compreende a matéria/objeto enquanto informação existente, que atua em cooperação (e não em oposição) com o sujeito. Dito de outro modo, a "homeotecnologia" opera a partir de estratégias "co- 
inteligentes e co-informativas", criando novos estados de inteligência a partir das qualidades dos corpos (SLOTERDIJK, 2006, p. 17).

Esse parece o caso da possibilidade de transferência de genes entre humanos em que se usa um vírus inócuo para transferir genes de um corpo para outro. Aliás, esse procedimento pode ser compreendido enquanto estratégias co-inteligentes e co-informativas na medida em que o vírus da transferência genética, ao aportar no corpo destinatário, "descarrega os genes anormais, os quais podem começar a funcionar e produzir as proteínas e enzimas necessárias" (WORLD ANTI-DOPING AGENCY, 2005, p. 3) automaticamente, ou ainda, natural-artificialmente.

Portanto, o sujeito homeotecnológico seria aquele que rompe com as fronteiras dualísticas, que agrega a dispersão de fronteiras em si mesmo. No caso deste ensaio, o "atleta homeotecnológico" incorporaria todo o espaço de indefinição promulgado pelos órgãos controladores do esporte, ocuparia o não-lugar ou, dito de outro modo, os lugares nos quais os conhecimentos e modos de compreensão dualistas não puderam dominar. Tal sujeito seria fruto da crise de uma suposta autenticidade do indivíduo moderno, na qual a "a morte da naturalidade humana e sua dispersão e ambivalência" compõem o quadro atual das alterações humanas via tecnologias (MIAH, 2006, p. 316).

No entanto, esta concepção de atleta sofre dificuldades de posicionamentos tendo em vista que o "atleta homeotecnológico", ao ter conformações diferentes daquelas de seus concorrentes, a saber, o atleta normal e o paratleta, não poderia ser entendido como recebendo vantagens em relação aos seus concorrentes, independentemente do tipo de competição que participasse, seja da ordem dos atletas normais ou dos paratletas. Tal maneira de pensar, se ocorresse, seria limitada, pois o "atleta homeotecnológico" não pode ter como referente um par binário para comparações, tendo em vista que sua constituição está em outra ordem de organização, produção e pensamento. Entrementes, a WADA-AMA, ao posicionar-se sobre o uso do doping genético, por exemplo, o condena e repreende a partir do pensamento dualístico, na medida em que 
argumenta que o uso do doping genético "para uso ou melhoramento das habilidades atléticas é tão repreensível como qualquer tipo de dopagem tradicional" (WORLD ANTI-DOPING AGENCY, 2005, p. 1).

Assim, as relações modernas baseadas em pressupostos dualísticos e organizadas a partir de lógicas binárias entre natureza e cultura, ou ainda, natural e artificial, parecem limitadas para a compreensão, classificação e organização das transformações tecnológicas ocorridas nos corpos dos atletas contemporâneos, pois tais saberes e práticas biotecnológicas vêm confundir as antigas relações existentes entre os pares natureza/cultura ou natural/artificial, como o caso do novo tipo de atleta emergente, ou ainda, no caso do atleta citado no início desse estudo, Oscar Pistorius.

\section{Considerações}

Neste ensaio tive como objetivo explorar as possibilidades biotecnológicas contemporâneas e suas influências na constituição de novos sujeitos atletas ou esportistas. A partir das possibilidades de emergência de atletas contemporâneos, hibridados com as biotecnologias, e da difícil análise do que eles vem a ser quando o referencial é moderno e dualístico, é possível depreender que novos formas de compreensão do ser humano, e nesse caso dos atletas e do esporte de alto rendimento, são necessárias. Pressuponho que estas novas condições exijam novas formas de reflexões e organizações sociais e culturais. Sugiro, por fim, a continuidade das discussões sobre estas questões, tendo em vista que os avanços tecnológicos, na atualidade, acabam por ser mais velozes que nossas capacidades de assimilação e reflexão sobre estes temas. 
Athletes of the xxi century: biotechnological mergers in high performance athletes

Abstract: This study aims to discuss the contemporary conditions linked to biotechnologies and their relationships with elite sport, in particular, the configuration of a new kind of fellow athlete. For this discussion part of a specific case of the sports world to launch questions regarding this issue.It starts with the assumption that the epistemological foundations that organize modern sport is dualistic, and eventually classify individuals between athletes normal and paratletas, therefore, unable to cope with the changes of our day concerning the uses of technology to expand the potential human.

Keywords: Sports. Athletes. Biotechnology.

Atletas del siglo xxi: fusiones en deportistas de alto rendimiento

Resumen: Este estudio tiene como objetivo discutir las condiciones actuales relacionadas con la biotecnología y su relación con el deporte de élite, en particular, la configuración de un nuevo tipo de deportista. Para esta discusión parte del caso específico del mundo del deporte para lanzar preguntas sobre este tema. Se inicia con la suposición de que los fundamentos epistemológicos que organizan el deporte moderno es dualista, y, finalmente, clasifican a los individuos entre los atletas y paraatletas normales, por lo tanto, incapaz de hacer frente a los cambios de nuestro tiempo respecto a los usos de la tecnología para ampliar el potencial humano.

Palabras clave: Deportes. Atletas. Biotecnología. 


\section{REFERÊNCIAS}

BORÉM, Aluízio; SANTOS, Fabrício, R. Biotecnologia simplificada. 2. ed. Viçosa: [s.n.], 2004.

BU'LOCK, John. Biotecnologia basica. Zaragoza: ACRIBIA, 1991.

COUTO, Edvaldo. O zumbido híbrido. A filosofia ciborgue do corpo. Revista Margem, São Paulo, n. 13, p. 85-99, jun. 2001.

DIAS, Rodrigo G. Genética, performance física humana e doping genético: o senso comum versus a realidade científica. Revista Brasileira de Medicina do Esporte, São Paulo, v. 17, n. 1, p. 62-7, jan/fev. 2011.0.

FAUSTO-STERLING, Anne. Dualismos em duelo. Cadernos Pagu, Campinas, n. 1718, p. 9-79, 2001.

HARAWAY, Donna. Manifiesto Ciborg: el sueño irónico de un lenguaje común para las mujeres en el circuito integrado. Tradución Manuel Talens con pequeños cambios de David Ugarte, 1984. Disponível em <http://webs.uvigo.es/xenero/profesorado/ beatriz_suarez/ciborg.pdf>. Acesso em: 10 nov. 2012.

HUMANITY PLUS. Disponível em: <http://humanityplus.org/>. Acesso em: 30 ago. 2012.

MACHADO E SILVA, Regina Coeli. Um rosto para vestir, um corpo para usar: narrativa literária e biotecnológica. Horizontes antropológicos, Porto Alegre, v. 14, n. 29 , p. 151-188, jan./jun. 2008.

$\mathrm{MIAH}$, Andy. Rethinking enhancement in Sport. In: ANNALS New York Academy of Sciences. Disponível em: <http://www.andymiah.net/>. Acesso em: 15 nov. 2012.

ORTEGA, Francisco. Corporeidade e biotecnologias: uma crítica fenomenológica da construção do corpo pelo construtivismo e pela tecnobiomedicina. Ciência e Saúde Coletiva, Rio de Janeiro, v. 12, n. 2, p. 381-388, 2007.

RABINOW, Paul. Artificialidade e iluminismo: da sociobiologia à biossociabilidade In ANTROPOLOGIA da razão. Rio de Janeiro: Relume Dumará, 2002. p. 135-157.

RIFKIN, Jeremy. O seculo da biotecnologia: a valorização dos genes e a reconstrução do mundo. São Paulo: Makron, 1999.

ROSE, Nikolas. The politics of life itself: biomedicine, power, subjectivity in the twenty-first century. Princeton: Princeton University, 2007.

SCRIBAN, Rene. Biotecnologia. São Paulo: Manole, 1985. 
SIBILIA, Paula. O homem pós-orgânico: corpo, subjetividade e tecnologias digitais. Rio de Janeiro: Relume Dumará, 2002.

SILVA, Tomaz Tadeu. Documentos de Identidade: uma introdução às teorias do currículo. Belo Horizonte: Autêntica, 1999.

SLOTERDIJK, Peter. El hombre operable. Notas sobre el estado ético de la tecnología gênica. Revista Observaciones Filosóficas, Madri, mayo, 2006.

WORLD ANTI-DOPING AGENCY-AGÊNCIAMUNDIAL ANTIDOPING (WADA-AMA). Play True, n. 1, 2005. Disponível em: <http://www.wada-ama.org/>. Acesso em: 30 set. 2011.

Endereço para correspondência:

Rua Frederico Wolfgang Sênior, 134

Blumenau, Santa Catarina,

CEP 89036-470.

Recebido em: 09.09.2012

Aprovado em: 30.11 .2012

Movimento, Porto Alegre, v. 19, n. 01, p. 289-308, jan/mar de 2013. 